\title{
OPEN SOURCE APPLICATION FOR PROJECT MANAGEMENT
}

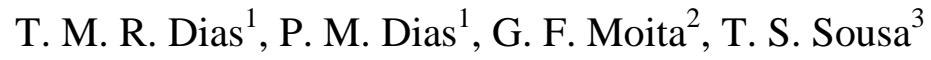 \\ ${ }^{1}$ Instituto de Ensino Superior e Pesquisa - INESP, Fundação Educacional de Divinópolis - \\ FUNEDI/UEMG
}

${ }^{2}$ Centro federal de Educação Tecnológica de Minas Gerais - CEFET-MG

${ }^{3}$ Instituto Federal Minas Gerais - IFMG

\begin{abstract}
Due to the highly competitive industry exists in software development and the quest for increasing product quality, project managers are required to adopt postures increasingly linked to meeting quality requirements and desires of its customers. The workaims to assistproject developers in the management and improvement in its processes, in order tobring higher quality, making themcapable of being more competitive. For this, we constructed a user-friendly web application for management of the entire process of developing a project, providing quality into the process. In this context, were incorporated into the tool project management practices that help managers and employees to meet particular needs and constraints and are still considered and specific features that the whole process needs.
\end{abstract}

Keywords: Web Application, Project Management, Process Quality, Open Source.

Resumo: Devido a grande competitividade existente no setor de desenvolvimento de software e a busca cada vez maior por produtos de qualidade, os gerentes de projetos são obrigados a adotar posturas cada vez mais vinculada ao atendimento a requisitos de qualidade e aos desejos de seus clientes. O trabalho desenvolvido pretende auxiliar as empresas que desenvolvem projetos na gerência e melhoria em seus processos, com o intuito de trazer maior qualidade, tornando-os capazes de serem mais competitivos. Para isto, foi construída uma aplicação web de fácil utilização para a gerência de todo o processo de desenvolvimento de um projeto, fornecendo qualidade ao processo. Neste contexto, foram incorporadas na ferramenta práticas de gerenciamento de projetos que auxiliem os gerentes e colaboradores a enfrentar necessidades e particularidades e ainda são consideradas restrições e características específicas que todo o processo necessita.

Palavras Chave: Aplicação Web, Gerência de projetos, Qualidade do Processo, Software Livre. 


\section{INTRODUÇÃO}

Com o aumento da competitividade, pequenos produtores têm que utilizar métodos e/ou ferramentas que possam ser implantados para auxiliar em todos os passos que contemplam o processo de plantio e colheita em suas propriedades. Esses métodos e ferramentas são aprendidos e praticados na busca pelo aperfeiçoamento contínuo e aumento da vantagem sobre os concorrentes.

"A qualidade deixou de ser um diferencial e tornou-se pré-requisito nos mais diversos setores da economia (indústria, serviços, agricultura)." [2]. A busca pela qualidade envolve todos os processos e etapas que compõem o projeto. É fundamental ter qualidade durante todas as fases de um projeto, desde a implementação até a finalização, passando por todos os diversos fluxos que o envolvem sendo necessário o comprometimento total por parte dos envolvidos. É imprescindível implantar novas formas de gerenciamento, para auxílio e controle, independentemente do tamanho do projeto que se pretende controlar.

O presente trabalho tem como propósito a criação de uma ferramenta para a gerência de todo o processo de plantio e colheita, seguindo técnicas de gerência de projetos de software.

Colocar todas as boas técnicas que a gerência de projeto recomenda em uma ferramenta computacional de fácil manipulação, permitindo que a mesma seja distribuída de forma livre de licenças e que aborde características e particularidades que os agricultores da região possuam, surge como uma alternativa viável para impulsionar a produção.

Acredita-se que estes produtores sendo auxiliados por uma ferramenta poderiam realizar um controle efetivo de todas as etapas que compõem o projeto, desde a plantação até a colheita de um determinado produto, realizando desta forma, o controle e designação de tarefas segundo um cronograma, aquisição de equipamentos, além de acompanhamentos de resultados.

\section{GERÊNCIA DE PROJETOS}

A Gerência de Projetos surgiu como uma disciplina nos Estados Unidos. "Seu precursor foi Henry Gantt, especialista em técnicas de planejamento e controle, que utilizou o gráfico de "barra" como uma ferramenta de gerência do projeto, associado às teorias de Frederick Winslow Taylor da administração científica.” [3].

"Um projeto é um esforço temporário empreendido para criar um produto, serviço ou resultado exclusivo." [5]. Para entender melhor o conceito de projeto, é importante fazer uma análise detalhada das características de um projeto:

\section{1 - Temporário}

O projeto é temporário, pois possui um início e um fim. O início do projeto é dado quando este é autorizado a ser iniciado por quem o encomendou, e chega ao fim quando os objetivos do projeto tiverem sido alcançados, quando se chegar a conclusão que os objetivos 
não serão ou não poderão ser alcançados ou quando o projeto não for mais necessário e for encerrado.

2 - Produto, serviço ou resultado exclusive

O projeto resulta em um produto, serviço ou resultado exclusivo, pois cada projeto resultará em um produto que possui características únicas. Mesmo que vários projetos busquem gerar um mesmo produto, cada produto tem suas características próprias e a presença de elementos repetitivos não muda a singularidade do projeto.

\section{3 - Elaboração progressive}

Um projeto é elaborado progressivamente, pois ele é desenvolvido inicialmente em linhas gerais e evolui à medida que seus objetivos e resultados sejam melhor entendidos.

Gerência de projetos, segundo o PMBOK [5], "é a aplicação de conhecimento, habilidades, ferramentas e técnicas às atividades do projeto a fim de atender aos seus requisitos".

Uma grande dificuldade a ser enfrentada pelo gerente de projeto, que é o responsável por realizar os seus objetivos, é conseguir atender as diversas necessidades que um projeto apresenta. Para o cumprimento de tal responsabilidade é necessário que o gerente do projeto tenha um grande conhecimento e habilidade pra equilibrar as diversas demandas conflitantes: escopo, tempo, custo, risco e qualidade; partes interessadas com necessidades e expectativas diferenciadas; e requisitos identificados e não identificados.

O gerenciamento de projetos é realizado através de processos que recebem entradas e geram saídas. "Processo é a sequência de passos, tarefas e atividades que convertem entradas de fornecedores em uma saída: produtos, resultados ou serviços." [1].

A Figura 1 mostra a relação entre os cinco grupos de processos:

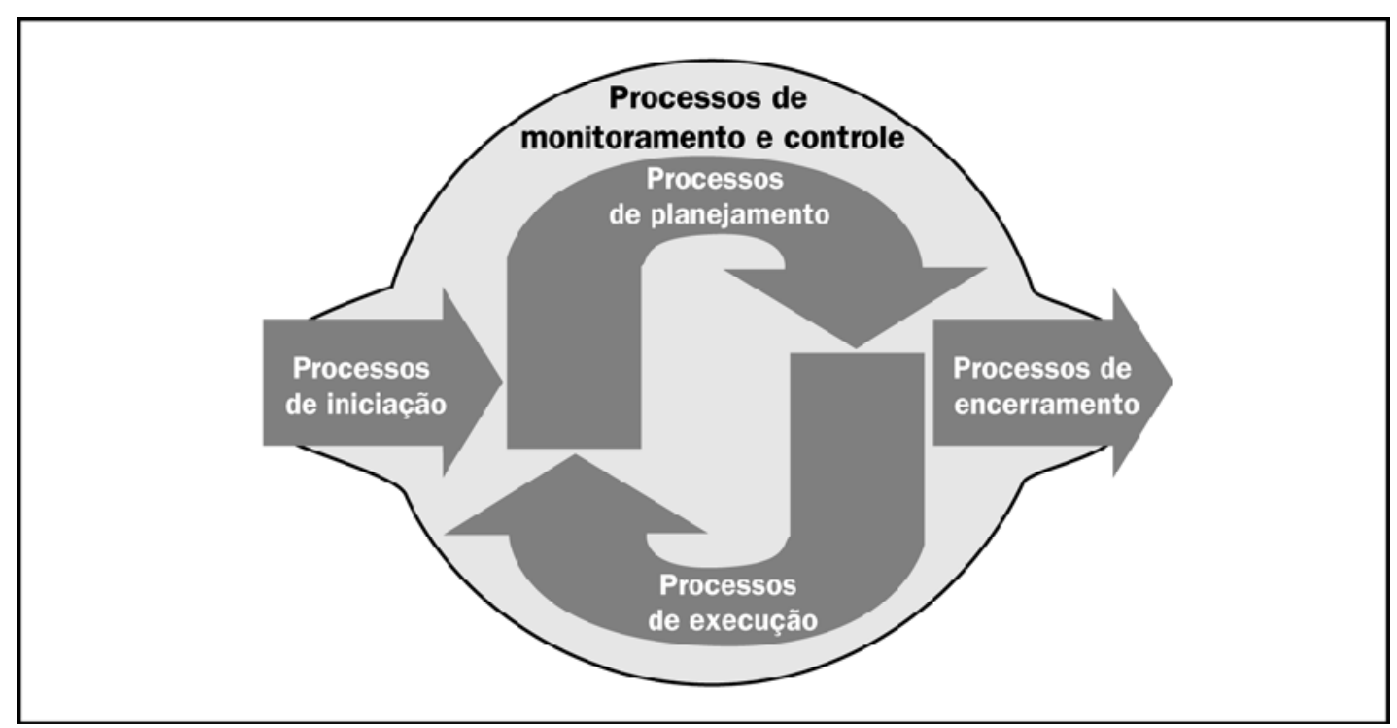

Figura 1. Grupos de Processos de Gerenciamento de Projetos. [5] 
Cada grupo de processo contém vários processos que são de extrema importância dentro da gerência de projetos, estes devem ser considerados durante toda a execução de um projeto pra que o mesmo tenha sucesso.

A Figura 2 mostra uma visão geral das áreas de conhecimento em gerenciamento de projetos e os processos de gerenciamento de projetos:

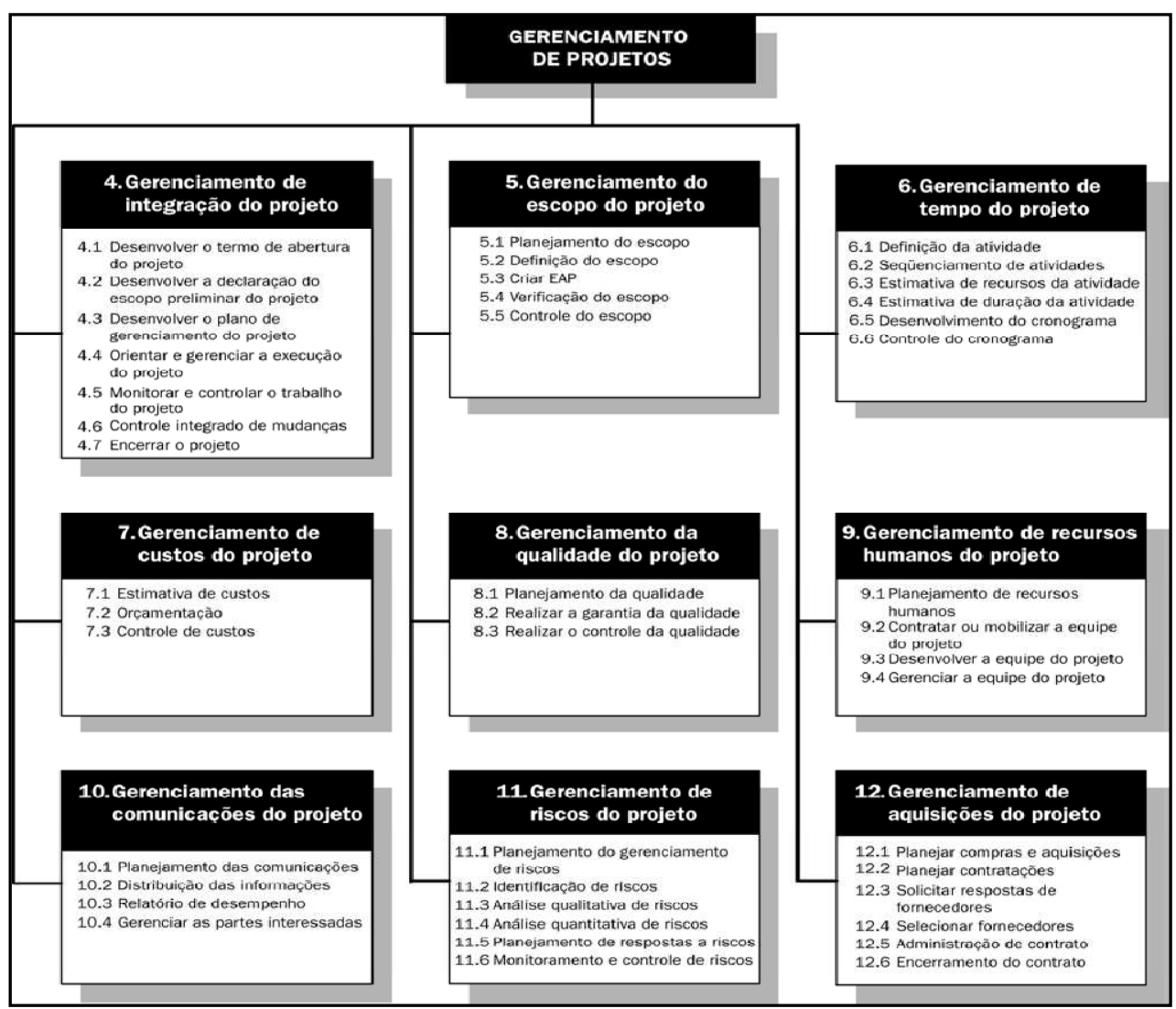

Figura 2. Áreas de conhecimento em gerenciamento de projetos e seus processos. [5]

Estas áreas de conhecimento são aplicadas ao longo dos grupos de processos de gerenciamento de projetos de forma matricial. Cada processo que faz parte das áreas de conhecimento é composto de entradas, ferramentas e técnicas, bem como saídas.

Para manter a qualidade de um projeto é de extrema importância o balanceamento de uma restrição tripla, o escopo, o tempo e o custo, pois a qualidade é diretamente proporcional ao equilíbrio desses três fatores. A relação entre esses fatores é tão forte que se um dos três fatores for alterado, pelo menos um dos outros dois também será.

Para o propósito desse trabalho será dado um maior foco nesses três fatores: o Gerenciamento do Escopo, o Gerenciamento do Tempo e o Gerenciamento do Custo. 


\section{FERRAMENTA CONSTRUÍDA}

Para o desenvolvimento da aplicação foram criadas classes usando a linguagem de programação Java e páginas JSP. Na criação das páginas foi utilizada uma combinação das tecnologias Java Server Pages (JSP) e Java Servlet, dessa forma, a tecnologia JSP foi empregada para realizar o controle de layout da página e incluir conteúdo dinâmico, enquanto que o servlet realiza o controle da aplicação.

O controle realizado pelo servlet funciona da seguinte maneira: todas as requisições são enviadas para o servlet, que processa a requisição e chama a página JSP apropriada para mostrar os resultados.

Para armazenar as informações dos projetos foi criado um banco de dados contendo várias tabelas que são responsáveis por armazenar os dados de todos os elementos que fazem parte do projeto. $\mathrm{O}$ acesso ao banco de dados do sistema é realizado por métodos contidos na classe Banco de Dados, que são chamados pelo servlet.

Para a criação do banco de dados, foi gerado o modelo lógico contendo todos os dados que são necessários armazenar para se ter um controle efetivo do projeto. Este modelo lógico permite a visualização de todos os componentes do projeto que serão gerenciados.

Na definição do que será gerenciado, o questionário aplicado foi um dos principais focos para realizar o levantamento inicial de requisitos. Com as respostas do questionário foi possível identificar que em um projeto agrícola existe maior dificuldade de gerenciar riscos e aquisições, e que as áreas mais importantes de gerenciar são tempo e recursos humanos.

Além do questionário, as pesquisas realizadas sobre Gerenciamento de Projetos também auxiliaram na definição de quais práticas devem ser gerenciadas e quais não se adéquam à ferramenta desenvolvida.

A primeira etapa do sistema é o cadastro da Empresa. A página de Login contém um botão que direciona para a página de Cadastro de Empresa, onde são cadastrados a empresa juntamente com um administrador, através dos métodos inseriEmpresa() e inseriUsuario(). $\mathrm{O}$ administrador é o responsável por cadastrar os demais usuários que poderão acessar os dados dos projetos de sua empresa, além de possuir alguns privilégios que os usuários comuns não possuem.

Cada empresa possui apenas um administrador que poderá ser modificado caso haja necessidade. A Figura 3 apresenta a tela principal da ferramenta. 


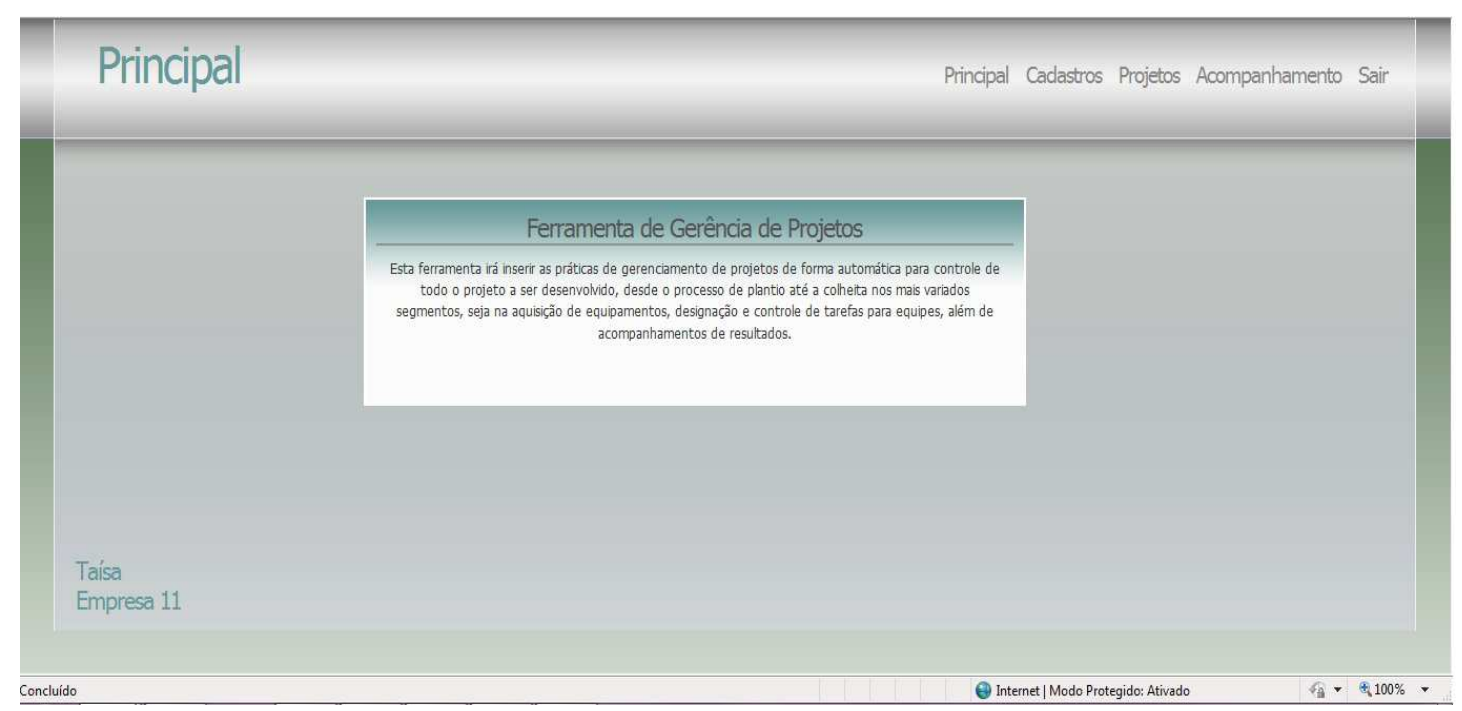

Figura 3. Página Principal

Na página de Cadastro de Produtos o usuário irá selecionar um fornecedor em um Drop-down, caso o fornecedor ainda não esteja cadastrado, a página contém um botão que direciona para a página de Cadastro de Fornecedor, na qual após o fornecedor ser cadastrado é redirecionado para a página de Cadastro de Produto. A mesma opção é oferecida ao usuário quando este necessita cadastrar um integrante do projeto porém, sua função não está cadastrada. Essas opções também são permitidas na alocação de integrantes e produtos disponível no menu Projetos.

O menu Projetos possibilita realizar o cadastro e alteração dos projetos da empresa, das atividades do projeto, marcar a atividade como concluída, cadastrar, alterar e excluir equipes das atividades, alocar e excluir integrantes da equipe, alterar os dias trabalhados do integrante, alocar e excluir o produto da atividade, e alterar a quantidade de produto alocado na atividade. Figura 4.

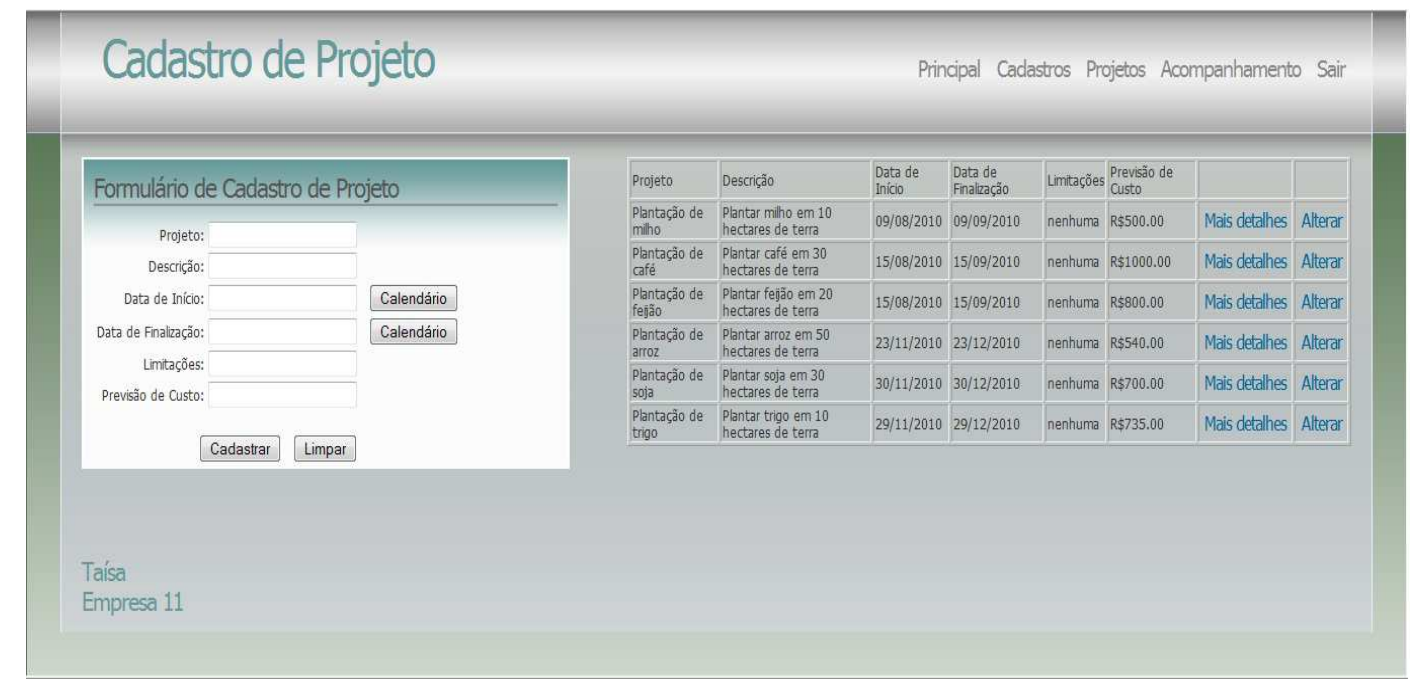

Figura 4. Página Cadastro de Projetos do Menu Projetos 
Todos os cadastros do menu Projetos são realizados de forma progressiva. Somente depois de cadastrar um projeto é possível cadastrar as atividades daquele projeto, em seguida alocar produtos na atividade ou cadastrar equipes e alocar integrantes para as equipes.

Quando uma pessoa é alocada em uma equipe é cadastrado o número de dias que esta pessoa trabalhou para posteriormente serem realizados os cálculos de custos do projeto. Os dias trabalhados podem ser alterados no botão Alterar dias Trabalhados caso a pessoa tenha que trabalhar mais dias do que foi cadastrado.

O mesmo acontece quando um produto é alocado na atividade, onde deverá ser cadastrada a quantidade de produto que será utilizado. A quantidade de um determinado produto alocado pode ser alterada no botão Alterar Quantidade de Produto caso a quantidade não seja suficiente e tenha necessidade de alocar mais.

Os cálculos de custos são realizados através da soma de gastos com pessoas e com produtos. $\mathrm{O}$ gasto com pessoas é calculado através da multiplicação do salário/dia cadastrado na página Cadastro de Integrantes, pelos dias trabalhados cadastrado na página Alocação de Integrantes na Equipe.

Já o gasto com produtos é calculado através da multiplicação do preço do produto cadastrado na página Cadastro de Produtos, pela quantidade de produtos utilizados cadastrado na página Alocação de Produtos na Atividade.

Atividades concluídas, Atividades no prazo e Atividades atrasadas, possibilita ao usuário selecionar um projeto e ver quais atividades estão dentro do prazo estipulado, quais estão atrasadas e quais já foram concluídas. Essa visualização também é possível na página Atividades do Projeto, onde as atividades no prazo estão em azul claro, as atividades atrasadas estão em vermelho e as atividades concluídas estão em verde claro. Na Figura 5 é mostrado o relatório gerencial de Atividades concluídas, Atividades no prazo e Atividades atrasadas.

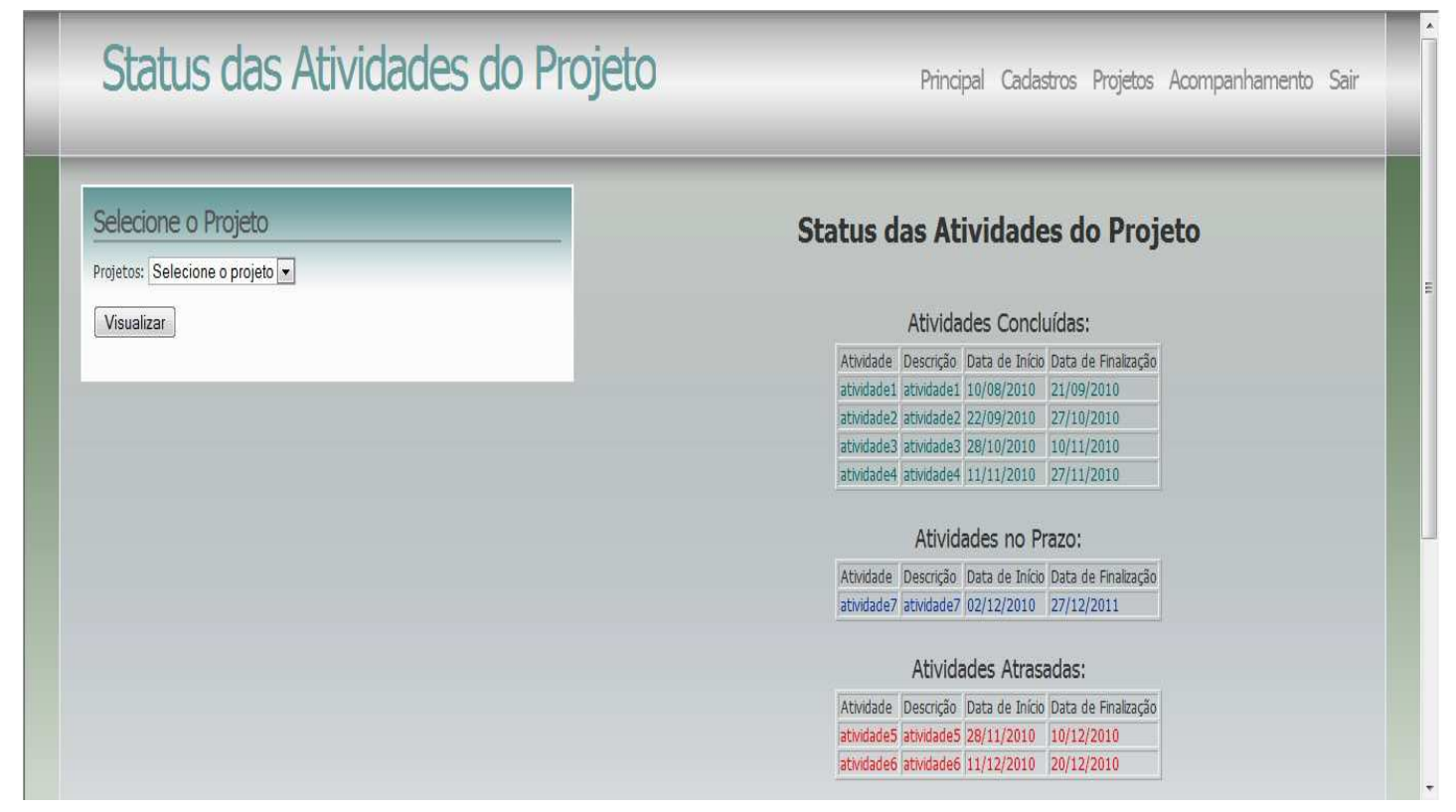

Figura 5. Página de Status das Atividades do Projeto 
A ferramenta também disponibiliza outra forma de controle de tempo das atividades. Quando o administrador faz login é realizada uma busca no banco de dados por atividades que terminam naquele dia, e se for encontrada alguma atividade que está prestes a vencer é enviado um e-mail ao administrador informando-o.

Para realizar esse controle de tempo das atividades, são cadastradas as datas de início e término da mesma que podem ser alteradas caso a atividade se estenda. Dessa forma, vendo quais atividades vão vencer ou estão atrasadas o usuário poderá redefinir a data final da atividade para que não comprometa o projeto.

\section{CONCLUSÕES}

De um modo geral, a agricultura além de ser uma das atividades de maior influência na economia do Brasil. Dessa forma, buscar práticas que melhorem a qualidade dos produtos e de todo o processo é uma forma de aumentar a competitividade dos agricultores.

A ferramenta proposta foi modelada com base em uma ferramenta de gerência de projetos de software, e modificada para atender as necessidades dos produtores rurais em seus projetos.

Devido ao fato da ferramenta ser gratuita e não precisar de treinamento por ser de fácil manipulação, poderá ser implantada em qualquer propriedade que queira informatizar os seus processos, e usufruir de um mecanismo que irá fornecer informações precisas em tempo hábil para tomada de decisões sem nenhum custo e esforço com aprendizado.

O trabalho mostra como a utilização de ferramentas de gerência de projetos na área agrícola pode resolver problemas de controle e monitoramento de projetos que são comuns aos produtores rurais.

Através de uma pesquisa foi constatado que os produtores rurais possuem grande dificuldade de gerenciar riscos, aquisições, recursos humanos e tempo. Dessa forma a utilização da ferramenta desenvolvida irá auxiliar na realização de controle de todos esses fatores que são críticos ao sucesso do projeto.

\section{REFERÊNCIAS}

[1] ARAGÃO, D. L. L. A. Uma Proposta de Gerenciamento de Projetos para Dispositivos Móveis Celulares. 2008. 46 f. Monografia (Bacharel em Ciência da Computação) - Centro de Informática - Universidade Federal de Pernambuco, Recife, 2008.

[2] COSTA, A. A. Ferramenta de Controle da Qualidade Aplicáveis na Cultura do Mamão, no Município de Pinheiros-ES. 2003. 72 p. Monografia (Graduação em Administração de Empresas) - Projeto de Graduação - Faculdade Capixaba de Nova Venécia - UNIVEN, Nova Venécia, 2003.

[3] DISNMORE, P. C. Gerenciamento de Projetos. Qualitymark, 2004. 
[4] FEDERAÇÃO DA AGRICULTURA E PECUÁRIA DE GOIÁS. Produtividade agropecuária do Brasil é uma das maiores do mundo, 2010. Disponível em: < http://www.faeg.com.br/index.php?option=com_content\&view=article\&id=7408\%3Aprod utividade-agropecuaria-do-brasil-e-uma-das\&catid=14\%3Aultimasnoticias \&Itemid=16>. Acesso em: 30 de novembro de 2010.

[5] Project Management Institute, PMI. Um Guia do Conjunto de Conhecimentos em Gerenciamento de Projetos: Guia PMBOK. Terceira Edição. Pennsylvania: Four Campus Boulevard, 2004. 388p.

[6] RAQUEL, T. Sustentabilidade e Agricultura, 2008. Disponível em: <http://www.webartigos.com/articles/5114/1/Sustentabilidade-Agricultura/pagina1.html> Acesso em 30 de novembro de 2010. 